\title{
The Impact Of Fun at Work on Creative Performance and Organizational Citizenship Behaviour
}

\author{
Herkin Prabowo ${ }^{1}$, Nayunda Andhika Sari ${ }^{2}$, Ayu Aprilianti ${ }^{3}$, Aryana Satrya $^{4}$ \\ ${ }^{1,2,3,4}$ Department of Management, Faculty of Economics and Business, Universitas Indonesia, Kampus UI \\ Depok, Indonesia \\ 2nayunda@ui.ac.id
}

\begin{abstract}
The growing numbers of millennial generation in the workforce have led to numerous changes in the way organisations work and how the jobs are managed. This includes where the work takes place, how we the work is organised, and how workers communicate. These changes require organisations to take into account millennial's preferences toward work and therefore adapt to the current development. One of the most popular trends among millennial workers is the implementation of fun at work. Using the SEM method, this study examines the impact of fun at work on organizational citizenship behaviour as well as creative performance, with the role of work engagement as the mediating variable. This study was conducted using quantitative method in which data was collected by distributing questionnaires to 250 employees. Results have shown that fun at work does not influence employees' work engagement but has direct influence on organizational citizenship behaviour and creative performance. Hence, work engagement does not have role as mediator in the relationship between fun at work and creative performance as well as organizational citizenship behaviour.
\end{abstract}

Keywords: Fun at Work, Work Engagement, Creative Performance, Organizational Citizenship Behaviour

\section{Introduction}

The increase of transparency and the growing influence of the millennial generation have led to numerous changes in the way organisations work and how the jobs are managed, where the work takes place, how we the work is organised, and how workers communicate. Over time, the employee composition of an organisation will begin to turnover, which in this case, the baby boomers and generation $\mathrm{X}$ is beginning to be replaced by the millennial generation. The millennial generation is known as the generation born between 1984 and 1996. According to Hershatter\& Epstein [1] the millennial generation is a generation starting with people born in 1980 who entered the labour market in 2000.

Millennial workers place a greater importance on an engaging job and seek pleasure through their jobs, or commonly known as having fun at work. A survey conducted by PwC found that the millennial generation seeks flexible jobs that provide work-life balance and provide 
international assignment opportunities, and these indicators are the key to a higher work satisfaction. This research was conducted on 44,000 employees, in which a quarter of the sample is the millennial generation, across PwC offices around the world. The research found that 64 per cent of the millennial employees want greater flexibility where they can also work from home aside from the office, and 66 per cent of the millennials want the opportunity to modify their work hours to accommodate their personal interest and still be connected to the organisation through technology. Another research conducted by BrightHR on 2,000 millennial workers found that the integration of fun in the workplace can lower employee absence, increase productivity and reduce stress. This research also found that 79 per cent of graduate respondents believe that fun at work is important, 21 per cent believe that fun at work enforces stronger work ethics. The above data and facts indicate that the concept of fun at work needs to be taken into consideration because it directly correlates with the millennial generation that will make up the different lines of organisations.

Another previous research on the fun at work was conducted by Fluegge [2] and found that the concept reflects the incorporation of fun and humour in an individual's social, interpersonal and work engagements which provides an entertaining, comfortable and fun environment. This concept is in line with Lamm and Meeks [3] that defined workplace fun as a playful, social, interpersonal, recreational work engagement that is intended to provide entertainment, comfort and pleasure. A research conducted by Rockman [4]found that fun, creativity and humour positively affect workers by decreasing absence, retaining competent employees and lower turnover rate. With the provision of fun at work, employees are expected to display positive behaviour, be motivated in their work and provide their best effort.

This expectation is in line with the concept of Organisational Citizenship Behaviour (OCB), Creative performance and work engagement. This concept is defined as a behaviour outside of an employee's formal job responsibility that contributes to the psychological and social environment of a workplace [5] Furthermore, according to Fluegge [2], OCB is a voluntary behaviour of an individual that is not included in their job description but is indirectly recognised in the formal reward system and can increase the effectiveness an organisation's operation. OCB correlates with the turnover rate, decreases employee absence, increases productivity and work satisfaction [6] [2]defined that fun positively affect the OCB, Creative Performance and Work engagement.

According to Indonesia Central Bureau of Statistics, there are about 83 million people aged 2040 years old, categorized as millennial generation, who are in the productive age. This figure shows that millennial accounts for $34 \%$ of the total Indonesian population. Considering the number of millennials entering the workforce by 2020, organisations in Indonesia should prepare their working environment to better suit the millennial generation, and one of the ways is to apply the concept of fun at work in the workplace. Researches on the fun at work also found different results. Several studies found that the concept of fun in the workplace is important to create a positive impact on workers and the organisation. Fluegge [2]found that fun affects the performance of working undergraduate students where it positively affects task performance, creative performance and organisational citizenship behaviour. However, several types of research on the fun at work showed opposing results [2] According to [3] the concept of fun cannot be tolerated by everybody because they do not share the same perception of it as well as the perception on other concepts pertaining to fun in the workplace. An example is a research conducted by Fleming [7] which indicated that several employees find that the application of fun in the workplace as fake and inauthentic.

This research examines the correlation between fun at work and the variable of organisational citizenship behaviour creative performance with a mediating variable of work engagement. This research utilises a quantitative method with data collection through questionnaires. Purposive 
sampling technique is used with the target respondents of 250 employees. This research intended to be a reference for companies and relevant parties on the application of fun at work in Indonesian workplace.

\section{Literature Review}

Fun at work is defined as an experience where an individual is socially or interpersonally involved in the completion of their workload and conducts it in a fun and humorous manner, which as a result provides the individual with an entertaining, comfortable and fun environment [2], [3];[8] also defined fun at work as a behaviour that does not necessarily relate to work but is fun, entertaining and filled with pleasure. Fun at work can be created when the workplace environment is designed to make employees feel comfortable and find a sense of pleasure in their work; with the humorous interaction between employees and having other activities that create a sense of fun. Fun can affect employees' perception of well being and relieve stress and improve their motivation which will impact the effectiveness of their job performance.

Several articles and studies on the fun at work found that an employee that displays fun behaviour will experience less stress, [9]; [10] lower turnover rate and absenteeism [11], [12] and feel more energised and motivated [7]

\section{a. Fun at work and Work engagement}

Schaufeli et al. [13] define work engagement as a positive motivational state and selffulfillment in work characterized by the existence of vigor, dedication, and absorption. In this study, it was explained that the dimensions of fun at work (socializing with workers, celebrating work, personal motivation and global fun at work) had a significant positive relationship with work engagement. So, the first hypothesis (H1) of this study is: Fun at work influences work engagement.

\section{b. Fun at work and Creative performance}

The relationship between fun and creative performance is often illustrated by increasing mental flexibility associated with humor[14] . Based on this explanation, it can be described that fun at work is able to entertain individuals through socialization, celebration, and personal freedom (McDowell, 2005). Entertainment can foster mental flexibility and produce higher level of creative performance because fun at work is conceptually similar to the humor discussed earlier. So, the second hypothesis (H2) from this research is: Fun at work influences creative performanceThis section must be in one column.

\section{c. Fun at work and Organizational Citizenship Behavior}

According to Fluegge [2] fun at work is defined as individual participation in social, interpersonal or activities with fun and humorous tasks that provide the individual an entertaining, comfortable and pleasant atmosphere. Previous research shows that fun at work has a positive and significant influence on organizational citizenship behavior [2] So, the third hypothesis (H3) in this study is: Fun at work influences work engagement.

\section{d. Work Engagement and Creative Performance}

Research conducted by LeFevre [15] has measured the relationship between flow and creative performance by using 1,026 samples of workers from five large companies. The results found a positive relationship between experienced flow and creativity. In this study, it was explained that the more frequent research participants felt the experienced flow, the greater the creative 
performance they performed. This study provides preliminary evidence to prove that flow is positively related to creative performance because the absorption of work engagement dimension is considered to be similar to flow. Therefore, work engagement also has a positive relationship with creative performance. So, the fourth hypothesis $(\mathrm{H} 4)$ from this research is: Work engagement influences creative performance.

\section{e. Work engagement and Organizational Citizenship Behavior}

Previous studies have suggested that there is a significant positive relationship between work engagement and organizational citizenship behavior [16] This is also supported by Ziyad which shows that job satisfaction, work attachment, and personality significantly influence organizational citizenship behavior with job satisfaction has a greater influence. So, the fifth hypothesis (H5) of this research is: Work engagement influences organizational citizenship behavior.

The research model is thus formulated as shown in Figure 1.

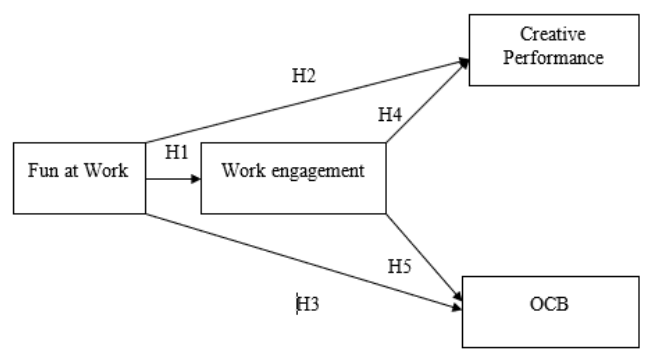

Fig. 1. Fun at work conceptual model

\section{Method}

\section{a. Research Sample}

The usage of 245 respondents in this research adheres to the rule of thumb in the SEM in which data processing requires a minimum of the sample that is 5 times the number of parameters in the research question, which amounts to 247 parameters [17] The requirement for the research respondents is to have worked in their organisation for at least one year. This is due to the expectation that such employees have experienced fun at work which would then influence their OCB behaviour and creative performance. The number of samples that were successfully processed in this research is 251 samples.

\section{b. Research Instrument}

This research utilised four instruments comprising of fun at work to measure the variable of fun at work developed by McDowell [8] which consists of 24 questions, and another instrument developed by Schaufelli and Bakker [13] to measure the engagement variable using 9 indicator questions. Moreover, the questionnaire developed by Georger and Zhou [18] was used to measure creative performance with 6 indicator questions, and lastly, the OCB variable was measured using 8 questions [19] All the questionnaires have been adapted into the Indonesian language consisting of 47 items with a Likert scale of 1-5. 


\section{c. Research Procedure}

This research utilised the research model developed from the literature on the fun at work, work engagement, creative performance and OCB, which are the topics that are currently debated in the working environment. The object of research pertaining to the topics has been conducted in multivariate workplace environments from private organisations to national and multinational organisations. In this research, the research object is the employees that have worked in their organisation for at least one year. The research was conducted in three months between late March and early May of 2018.

\section{Results}

Based on the results from the validity and reliability test of the measurement model below, all variable seems to have a good level of validity which can be seen from the SLF value $\geq 0.50$, and has a good level of reliability of the $\mathrm{CR} \geq 0,70$ and $\mathrm{VE} \geq 0.50$. In this study the $\mathrm{CR}$ value from all variables is $\geq 0,70 \mathrm{VE}$ value is $\geq 0.50$.. Hatcher (1994) states that in some studies, the value of VE is found to be $<0.50$ and this does not need to be disputed, as far as the CR value shown is $\geq 0.60$, so the reliability of all variable on this model is well.

\begin{tabular}{|c|c|c|c|}
\hline Variabel & $\sum$ SLF & CR & VE \\
\hline Fun at Work & 3,87 & 0,819 & 0,433 \\
\hline $\begin{array}{c}\text { Work Engagement } \\
\text { Creative } \\
\text { Performance }\end{array}$ & 3,79 & 0,886 & 0,469 \\
\hline OCB & 2,01 & 0,838 & 0,387 \\
\hline \multicolumn{2}{|c|}{} & 0,823 & 0,293 \\
\hline
\end{tabular}

Table 1. Summary of reliability and Validity

These variables have dimensions with the highest SLF value, namely the socializing dimension in the fun at work variable with the SLF value 0.70, the dedication dimension in the work engagement variable with the SLF value 0.85 . While for the creative performance indicator, CP5 indicator has the highest SLF with SLF value 0.68 and OCB4, OCB5, OCB6 indicators in organizational citizenship behavior with SLF value 0.71.

In the two-tailed hypothesis, if the t-value $\geq 1.96$ or $\leq-1.96$, the relationship is interpreted as significant and therefore answer the hypothesis. While, regarding the direction of its influence, the negative value means the exogenous variable has a negative influence towards endogenous variables, and positive values means the exogenous variable has a positive influence towards endogenous variables [17] The table below shows the results of the hypothesis tested in this study: 
Table 2: Summary of causal relationship analysis

\begin{tabular}{|c|c|c|c|}
\hline Hypothesis & Path & $\begin{array}{c}\text { T- } \\
\text { Value }\end{array}$ & Result \\
\hline 1 & $\begin{array}{c}\text { Fun at work } \rightarrow \text { Work } \\
\text { engagement }\end{array}$ & 1.25 & $\begin{array}{l}\text { Negative } \\
\text { Influence }\end{array}$ \\
\hline 2 & $\begin{array}{c}\text { Fun at work } \rightarrow \text { Creative } \\
\text { performance }\end{array}$ & 4.79 & $\begin{array}{l}\text { Positive } \\
\text { influence }\end{array}$ \\
\hline 3 & Fun at work $\rightarrow O C B$ & 4.22 & $\begin{array}{l}\text { Positive } \\
\text { influence }\end{array}$ \\
\hline 4 & $\begin{array}{c}\text { Work engagement } \rightarrow \\
\text { Creative performance } \\
\text { Work engagement } \rightarrow \text { OCB }\end{array}$ & 4.39 & $\begin{array}{l}\text { Positive } \\
\text { influence } \\
\text { Positive } \\
\text { influence }\end{array}$ \\
\hline
\end{tabular}

H1 predicted that Fun at work would be positively related to work engagement. It was found that the proposed hypothesis is rejected. Based on the research analysis, fun at work has no direct effect on work engagement as seen from the insignificant t-value of 1.25. which implies that the work engagement variable does not mediate fun at work.

H2 Predicted that Fun at work would be positively related to creative performance. , fun at work is proven to significantly influence creative performance with the t-value 4.79 .

H3 Predicted that Fun at work would be positively related to OCB, fun at work is proven to significantly influence OCB with the t-value 4.22.

H4 predicted that work engagement would be positively related to creative performance, work engagement is proven to significantly influence OCB with the t-value 4.39.

H5 predicted that work engagement would positively relate to OCB work engagement is proven to significantly influence OCB with the t-value 3.55 .

\section{Discussion}

There is no apparent two-tailed correlation occurring in the result of this hypothesis. Therefore, when fun at work is taken into consideration in the formulation of a job description, the employees' sense of engagement with their work environment is not affected. This may be a result of different factors that may stronger affect the employees' sense of engagement, namely organisational culture, career development within the organisation and salary level among others. This also shows that the more fun the work environment is, the more parties are being held, and the closer employees are with each other; it does not necessitate a higher engagement of 
employees with their work. This variable does not mediate between work engagement and creative performance as well as OCB.

This finding is in accordance with the highest SLF value of the fun at work variable, namely the socializing dimension. It can be explained that the more often individuals socialize in their work environment; it will be directly proportional to the level of fun. On the other hand, the highest SLF value from the work engagement variable is dedication. According to this finding, the more individual socializing within an organization does not necessarily mean that the individual has strong dedication to his/her work. Another finding in this study is that although fun at work has no effect on work engagement, fun at work has a positive effect on creative performance. This study found that in the context of Indonesian culture, the people have different interpretation of the concept of fun at work compared to other context as discussed by previous studies in different culture. This is shown by the highest SLF value of fun at work is socializing, which means the concept of fun at work in Indonesia is more defined as socialization among individuals in an organization compared to celebration or personal freedom.

The second hypothesis can be seen that the Fun at work variable significantly influences creative performance from the employees. Both variables have a significant effect on each other, this can be seen from the relationship between the most dominant dimensions and indicators of the two variables. The socializing dimension as the most dominant dimension in the Fun at work variable which has indicators in it such as socializing with colleagues inside and outside the office, building friendships in the office and sharing food in the office are correlated with the most dominant indicators of creative performance when employees come up with ideas, creative and innovative ideas.

The next hypothesis between the variables of fun at work and ocb has a significant effect on this relationship. It can be seen from the most dominant dimensions of the two variables. The socializing dimension as the most dominant dimension in the Fun at work variable, the indicators in it such as socializing with colleagues inside and outside the office, building friendships in the office and sharing food in the office are correlated with the most dominant dimensions of OCB namely civic virtue and sportmanship which indicators in it such as helping co-workers clearly have correlation with each other.

Furthermore, the hypothesis between work engagement and creative performance variables has a significant effect on this relationship, which can be seen from the most dominant dimensions and indicators of the two variables. variable work engagement the most dominant dimension is dedication which indicators in it such as feeling proud and enthusiastic about work and creative performance variables have the most indicators when employees emerge with new and creative ideas. These two things certainly have a correlation when employees who are enthusiastic and proud of their work according to the employee's researchers tend to be more creative.

The last is the relationship between work engagement variables and OCB. Both variables have a significant effect on this relationship, which can be seen from the most dominant dimensions and indicators of the two variables. The most dominant variable of work engagement dimension is dedication, the indicators of which are like being proud and enthusiastic about work and the most dominant dimension variables of OCB, namely civic virtue and sportmanship, the indicators of which are like helping co-workers clearly have correlation with each other. This can be linked to the more enthusiastic employees, the more proud they will be and defend their work while being criticized and employees will be more proud to represent their work in public.

\section{Conclusion}

Fun at work has no effect on work engagement. The largest dimension of this concept is not the employees' social activities. This shows that fun at work is not directly proportional to the 
level of engagement felt by the employees. The largest dimension of work engagement is dedication, where even though the employees may be more social, it does not mean that they have a higher level of dedication to the company. Through this research, it was found that the fun at work has a direct impact on creative performance and Organisational Citizenship Behaviour (OCB). Fun at work affects creative performance. It can be seen that the implementation of fun at work will improve employees' creative performance in their work. The fun at work experienced by employees comprised of social engagement with colleagues, the feeling of attaining success in the workplace and personal freedom, which all improves employees' creative performance. Fun at work affects OCB. This means that when a company implements fun at work, employees' OCB level increases. The fun at work experienced by employees comprised of social engagement with colleagues, the feeling of attaining success in the workplace and personal freedom, which all improves employees' positive attitude towards the company. Work engagement affects creative performance. This explains how a higher engagement level will motivate employees to perform more creatively and then work engagement affects OCB. This proves that with a higher the level of engagement, employees will display more OCB behaviour.

Fun at work has no effect on work engagement. This means that work engagement does not mediate between fun at work and creative performance as well as OCB. This can be seen from how the concept of fun at work used in this study pertains to the socialising conducted among colleagues, such as telling each other stories and building a friendship at the office. This is in line with how the level of dedication is the dimension where the work engagement is found to be at the highest level. Therefore, despite the socialising that the employees do among each other, it does not necessarily mean that their dedication to the company is impacted.

\section{Limitation}

The results obtained through this research still has many flaws and limitations which require improvements in the future. The following are suggestions to be considered in further research:

The research on the fun at work should be done as a case study on the companies that have applied this concept. For example, the companies that have the supporting facilities such as a playground or have implemented flexible working hours and casual dress code. Open-ended questions on the suitable implementation of fun at work may also be asked in the research. So for the further, exploratory research on the perception of Indonesian respondents about fun at work may also be conducted since the concept is still perceived differently in Indonesia.

Indicator questions on the fun at work need to be re-tested. This can be done by way of wording (testing the respondents' understanding of the indicators in the questionnaire) to reach a deeper understanding of what the research seeks to measure. And then new information on the same topic can also be researched, such as whether the fun at work concept can negatively impact an organisation as it may encourage counterproductive behaviours that would have a detrimental impact to the company or organisation.

\section{References}

[1] L. Herscovitch and J. P. Meyer, "Commitment to organizational change: extension of a three-component model," Journal of applied psychology, vol. 87, no. 3, p. 474, 2002.

[2] R. Fluegge-Woolf and E., "Play hard, work hard: Fun at work and job performance," Management Research Review, vol. 37, no. 8, pp. 682-705, 2014.

[3] E. an. M. Lamm and M.D., "Workplace fun: the moderating effects of generational differences,” Employee Relations, vol. 31, no. 6, pp. 613-631, 2009. 
[4] H. M. Z. Al-Bogami, "The relationship between transformational managemenet and communication skills among heads of departements of," KAU. Procedia Computer Science, vol. 65, pp. 1160-1164, 2015.

[5] S. P. Robbins and Judge, Organizational Behavior, 11th ed. New York: John Wiley and Sons, 2007.

[6] V. C. Prabowo, "Pengaruh Servant Leadership dan KomitmenOrganisasionalKaryawanterhadap Organizational Citizenship Behavior (OCB) pada Blue Bird Group Surabaya,” Agora, vol. 1, no. 3, pp. 1521-1532, 2013.

[7] R.-P. Beltrán-Martín, Escrig-Tena, and BouLlusar, "Human Resource Flexibility as a mediating variable between high-performance work systems and performance," Journal of Management, vol. 34, pp. 1009-1043, 2008.

[8] T. McDowell, "Fun at work: scale development, confirmatory factor analysis, and links to organizational outcomes", Doctoral dissertation, Alliant International, vol. 65. University, Alhambra, CA: Dissertation Abstracts International, 2004.

[9] M. Madsen and John, "Readiness for organizational change: Do organizational commitment and social relationship in the workplace make a difference," Journal Western Academy of Management, 2005.

[10] S. L. McShane, V. Glinow, and M. Ann, Organizational Behavior, 4th ed. New York: McGraw-Hill Companies, Inc, 2009.

[11] N. Vafeas, "Board meeting frequency and firm performance," Journal of Financial Economics, vol. 53, no. 1, pp. 113-142, 1999.

[12] V. N, "Board meeting frequency and firm performance. Journal of Financial Economics, 53 (1), 113-142.," 1999.

[13] W. B. an. B. Schaufeli and A.B., "Job demands, job resources, and their relationship with burnout and engagement: a multi-sample study," Journal of Organizational Behavior, vol. 25, no. 3, pp. 293-315, 2004.

[14] J. K and N. P, "Risk-based capital, portfolio risk, and bank capital: A simultaneous equations approach. Journal of Economics and Business, 49(6), 533-547.," 1997.

[15] J. LeFevre, "Flow and the quality of experience during work and leisure," in Optimal Experience: Psychological Studies of Flow in Consciousness, M. an. C. Csikszentmihalyi and I.S., Eds. New York, NY: Cambridge University Press, 1988, pp. 307-318.

[16] J. Sarkis, P. Gonzales-Torre, and B. Adenso-Diaz, "Stakeholder pressure and the adoption of environmental practices: The mediating effect of training," Journal of Operations Management, vol. 28, no. 2, pp. 163-176, 2010.

[17] S. H. Wijanto, Structural Equation Modelling with LISREL 8.8. Yogyakarta: GrahaIlmu, 2008.

[18] J. M. an. Z. George and J., "Understanding when bad moods foster creativity and good one's don't: the role of context and clarity of feelings," Journal of Applied Psychology, Vol.87, vol. 4, pp. 687-697, 2002.

[19] K. an. A. Lee and N.J., "Organizational citizenship behavior and workplace deviance: the role of affect and cognitions," Journal of Applied Psychology, vol. 87, no. 1, pp. 131-142, 2002 . 